\title{
BIBLIOMETRIC ANALYSIS OF QUANTITY AND QUALITY OF NIGERIA'S BIOMEDICAL LITERATURE
}

\author{
Dr. Williams E. Nwagwu \\ Africa Regional Centre for Information Science, \\ University of Ibadan, Nigeria
}

\begin{abstract}
The empirical evidence on the biomedical literature of Nigeria was drawn from 295 journals in Medline through which papers on Nigeria were published during the period 1967-2002. We categorized the journals according to their subject heading and examined the potential impact factors of a sample of the journals based on Thomson's ISI Journal Citation Reports. Multidisciplinary journals and papers dominated the source types and were also more highly co-authored than the other subject headings; they also have the highest potential impact factor. The implications of this pattern of journal choice on biomedical research in Nigeria are highlighted.
\end{abstract}

\section{Introduction}

Principally during the $20^{\text {th }}$ century, several studies were carried out to determine the characteristics of subject literatures and the relative importance of different kinds of publications in various fields. The earliest studies, as well as the great majority of the later ones, were based on an analysis of library records and a tabulation of published materials covered by abstracting journals and bibliographies or on reference counting, that is, tabulating footnotes and other literature references in journals, dissertations, and books (Brodman \& Taine. 1959). These studies have shed light on such issues as trends in publication, the relative importance of different special fields, title dispersion, subject scattering, time span or period of usefulness, language distribution of pertinent literature, and the national origin of materials. Several reference-counting studies have produced lists of the periodicals most frequently cited in the literature to aid libraries in the selection of periodicals in different subjects, among other purposes. Although 
bibliometric studies have grown beyond the level of publication analysis, many communities have yet to utilize them as a strategy for gathering information that could be useful in understanding their local science. This is exactly the situation in many developing countries, including Nigeria. The reasons for this situation have been exposed elsewhere (Nwagwu, 2005) where further explanations for the absence of bibliometric studies on the crucial field of biomedicine-defined by Medline as consisting of medical and biological disciplines—-were also provided.

In this paper, we want to examine the quantity and quality of biomedical publications related to Nigeria that have been disseminated through primary channels. This information would indicate the extent to which the resources invested in research and researchers have produced material scholarly results that have been shared among other scholars during the period. In Nigeria, research takes place within an environment of social, political, and economic constraints, orchestrated by many years of colonial rule, in addition to homegrown problems of economic mismanagement and official corruption. The quantity and quality of biomedical publications in Nigeria could provide insight into the pattern and core competencies of research defined as areas of specialized expertise which are indicative of the complex streams of technology and work activity common among scientists (Prahalad \& Hamel, 1990). In this article, we discuss the quality and quantity of the journals and papers without necessarily describing the individual journals, another project we undertake in another paper. 


\section{Data and Methods}

The empirical evidence used in this article was based on a cross-sectional bibliographic listing in Medline consisting of 6820 single and multiple author papers on Nigeria covering the period 1967-2002. We counted the number of papers, number of authors per paper, and page volume size of the papers and listed by name the journals in which the papers were published.

Based on the Library of Congress subject headings and the descriptions listed in Ulrich International Periodicals Directory and parameters outlined by Klein (1996), each of the journals and papers was assigned a subject designation as follows: multidisciplinary journals, broad-scope journals, fission journals, fusion journals, problem-centred journals, or other journal category. Multidisciplinary journals refers to those journals and papers that encompass many disciplines, broad-scope journals to those journals and papers that focus on a wide discipline, fusion journals to interaction between two or more disciplines, and fission journals to differentiation among disciplines. The journals that could not be classified into these categories were grouped as others. Examples of journals in each category that published papers on Nigeria are shown in Table 1.

Table 1: Categorisation of the journals by subject heading (SH)

\begin{tabular}{|l|l|}
\hline Subject heading & Examples \\
\hline Multidisciplinary & $\begin{array}{l}\text { African Journal of Medicine and Medical Sciences, British Journal } \\
\text { of Medicine } \\
\text { African Journal of Reproductive Heath, American Journal of } \\
\text { Family Planning } \\
\text { Falcified Tissue International, Cellular Immunology, }\end{array}$ \\
Fusion & $\begin{array}{l}\text { Clinical and Experimental Hypertension, Community Dentistry and } \\
\text { Oral Epidemiology } \\
\text { Problem-centred } \\
\text { and Isotopes }\end{array}$ \\
\hline
\end{tabular}


Furthermore, we needed some insight into the quality of the publications based on the potential impact factor (PIC) of the journals. In this study we join Webster (2000) to calculate the potential impact category as the mean number of citations received by papers published in the journal over the period of their publication year and the four following years (designated $\left.\mathrm{C}_{0}-4\right)$. This is not the same as the conventional impact factor (IF) published annually by the Institute for Scientific Information. PIC has the advantage of covering a longer time period, which normally includes the peak year for citations to a research paper. Also, the Co-4 journal citation score can be directly compared with the citations received by the paper.

Since Medline does not index use (or citation) data, we identified 89.81\% (265) of those journals in Medline that included papers reporting research from Nigeria and that also appeared in Science Citation Index. We arranged the journals in alphabetical order by their names, from among which we selected a sample of 26 based on a systematic sampling scheme. We then constructed the PIC of the 26 journals based on five-year mean citation scores $\mathrm{C}_{0-4}$ of those journals from the Institute for Scientific Information's Mean Expected Citation Rates file for the periods 1990, 1992, 1994, 1996, and 1998. Papers before 1992 were classed under 1990, while those after 1994 were classed under 1994.

Table 2: Categorisation of journals by potential impact factor, based on fiveyear mean citation scores $\mathbf{C}_{0-4}$ values

\begin{tabular}{|l|l|l|}
\hline PIC & $\mathbf{C}_{\mathbf{0 - 4}}$ range & An Example \\
\hline 1 & Below 6 & African Journal of Medicine and Medical Sciences \\
2 & From 6 to 11 & Journal of Internal Medicine \\
3 & From 11 to 20 & International Journal of Cancer \\
4 & Above 20 & Journal of American Medical Association \\
\hline
\end{tabular}


Furthermore, we organized the papers according to their page number sizes as 1-5, 6-10, 11-15, and $>15$. The author field was analysed by counting the total number of authors per article and we used collaborative coefficient (CC) to compute the level of collaboration (Ajiferuke, Burrel \& Tague, 1988).

The word scientist is used here to denote anyone whose papers are published by any of the journals indexed in Medline. Also, paper refers to any item published by any of the journals/channels indexed in Medline while channels refers to the serial and other outlets in which the papers were published. We are limited in this analysis by the indexing policy of Medline, which excludes citation data, in addition to not being comprehensive of Nigeria's scholarly channels (Nwagwu, 2005).

\section{Results}

\section{Overall distribution of the publications and authorships in the journals (1967-2002)}

A total number of 295 journals published about 6820 unique papers on Nigeria, and this represents less than one percent of the total number of papers in Medline during 1967 to 2002. Since every article was identifiable by the journal in which it was published and every journal was repeated in the index as many times as it carried papers, the total number of papers would be equal to the total number of appearances of all the individual journals in the bibliography and vice versa.

Figure 1 shows that the distribution of the journals is multi-modal, and this is very significant, having both theoretical and empirical implications. Basically, the peaks represent the journals in heavy use while the clustered base represents those journals that are not heavily used. That is, within the entire dissemination channels of biomedical 
literature on Nigeria, which we can consider a colony, there existed sub-colonies whose number of publications on Nigeria is similar. The colonies represent groups of channels that shared some certain characteristics with respect to the publications they contain. This feature could be due to the social, political, economic, cultural or other conditions that either impeded or enabled scientists to use the channels during the period. Also, the multi-modal distribution of the channels could imply that there was a high correlation among the different colonies within the entire distribution. We can infer uniform factors of social, economic, political, and other circumstances that could have influenced the volume of papers published by these journals. As scientists have the tendency to use channels that are available and accessible to them, we can then interpret this result further to be a reflection of market forces, which make some journals to be more highly demanded or highly favourable than the others.

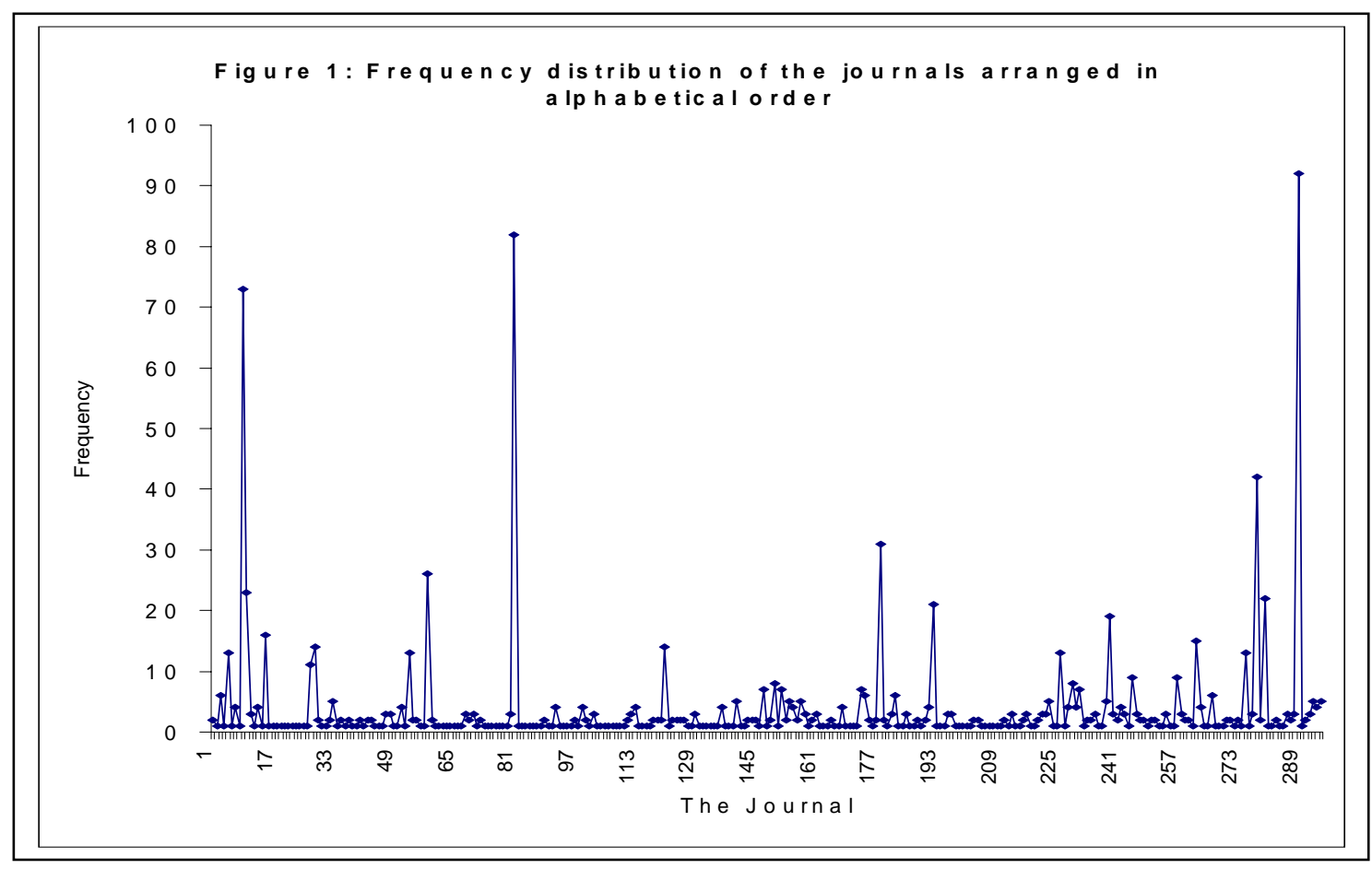

Pg 6 
In comparison with journals at the clustered base, the number of high peaks is small, which shows that only a very few journals constituted consistent channels to the biomedical scientists working on Nigeria. The fewness of consistent channels could be due to the lack of continued interest on the part of the scientists in using those journals, a result of high rejection rates of papers emanating from Nigeria by those journals, or attrition of the channels. The journals were further sorted in ascending order of the frequencies of their publications, and this gave a further understanding of the pattern of journal concentration on Nigeria as shown in Figure 2.

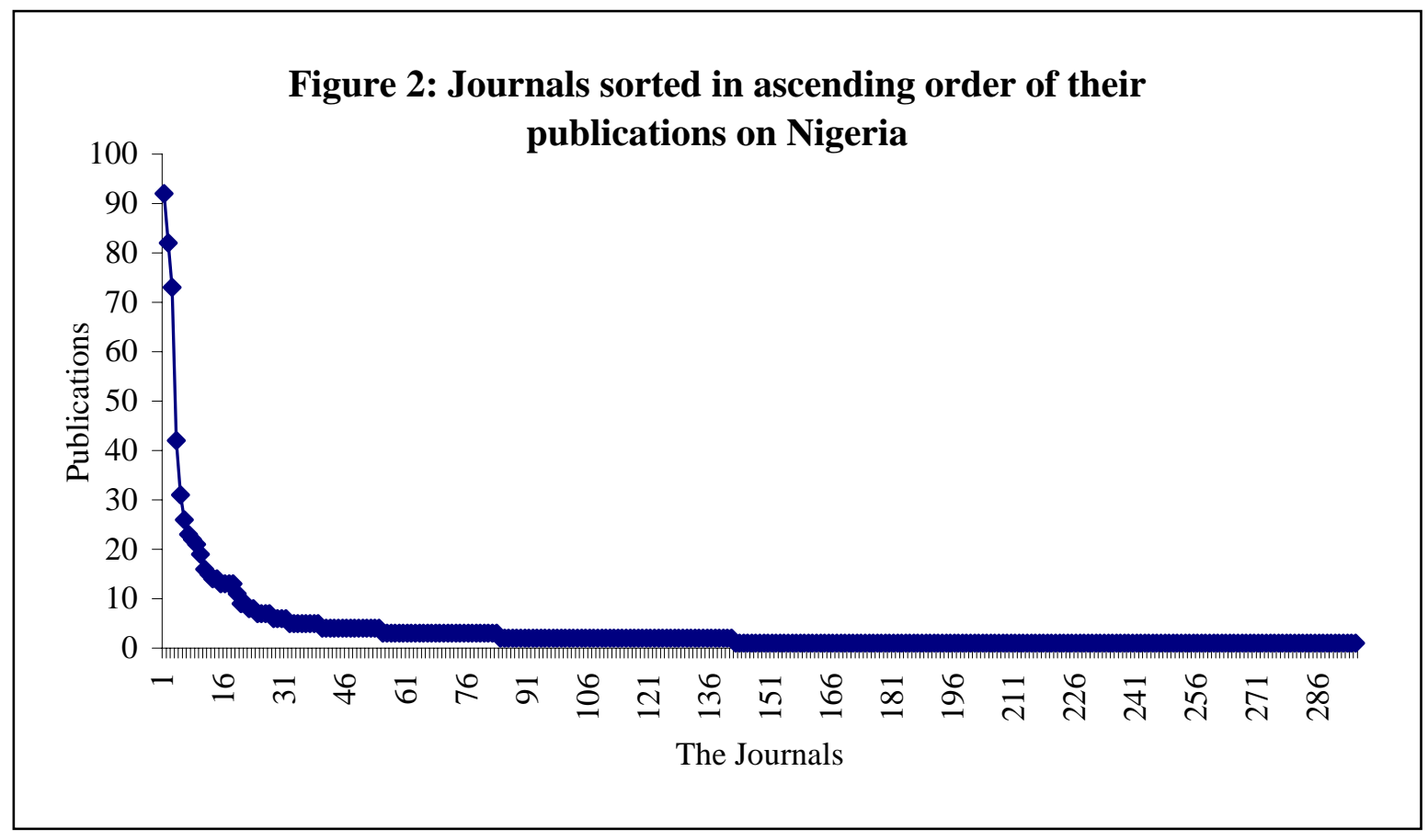

This figure shows clearly that the higher the number of expected papers focussing on Nigeria, then the fewer the number of journals meeting such an expectation, a bibliometric regularity of the distribution of sources over items often referred to as 
Zipfian class of distributions. Figure 2 confirms that a few journals were used to publish a large quantity of papers on Nigeria whereas a very large number of the journals published just a few papers. The physical form of the distribution conforms to the characteristics of bibliometric distributions, exhibiting an infinite moment and a long straggling tail where most significant producers are located.

We categorised the journals according to the number of their publications that reported research about Nigerian biomedicine and established that as many as 52\% of the journals appeared only once each in the bibliography while about $48 \%$ appeared more than once. The journals making single appearances contributed only $3.38 \%$ of the papers while the remaining $48 \%$ of the journals accounted, in varying degrees, for more than $96 \%$ of the papers. A breakdown of those journals producing more than one item shows that about $20 \%$, or 58 of the journals, appeared twice while about $10 \%$, or 29 journals, appeared three times. Only about $5.1 \%$, or 15 journals, appeared four times while eight journals (2.7\%) appeared five times and four journals (1.4\%) appeared six and seven times respectively. Two journals each $(0.7 \%)$ appeared eight and nine times respectively. Four (1.4\%) and two journals (0.7\%) each appeared 13 and 14 times respectively. Hence, as the number of expected appearances of journals increased, the number of journals making such appearances decreased more radically, to the extent that only three journals, or about $0.3 \%$, made at least 100 appearances each.

The journals, arranged in alphabetical order, also showed a very interesting authorship pattern, with some of the journals being heavily co-authored while the others were not. This is shown in Figure 3. Also, Figure 4 shows that annual publication figures also show some interesting results to the extent that the non-cumulated single author 
literature, multiple author literature, and total literature during 1967-2002 did not seem to show any discernible trend at all, the curves being characterised by unsteadiness in the

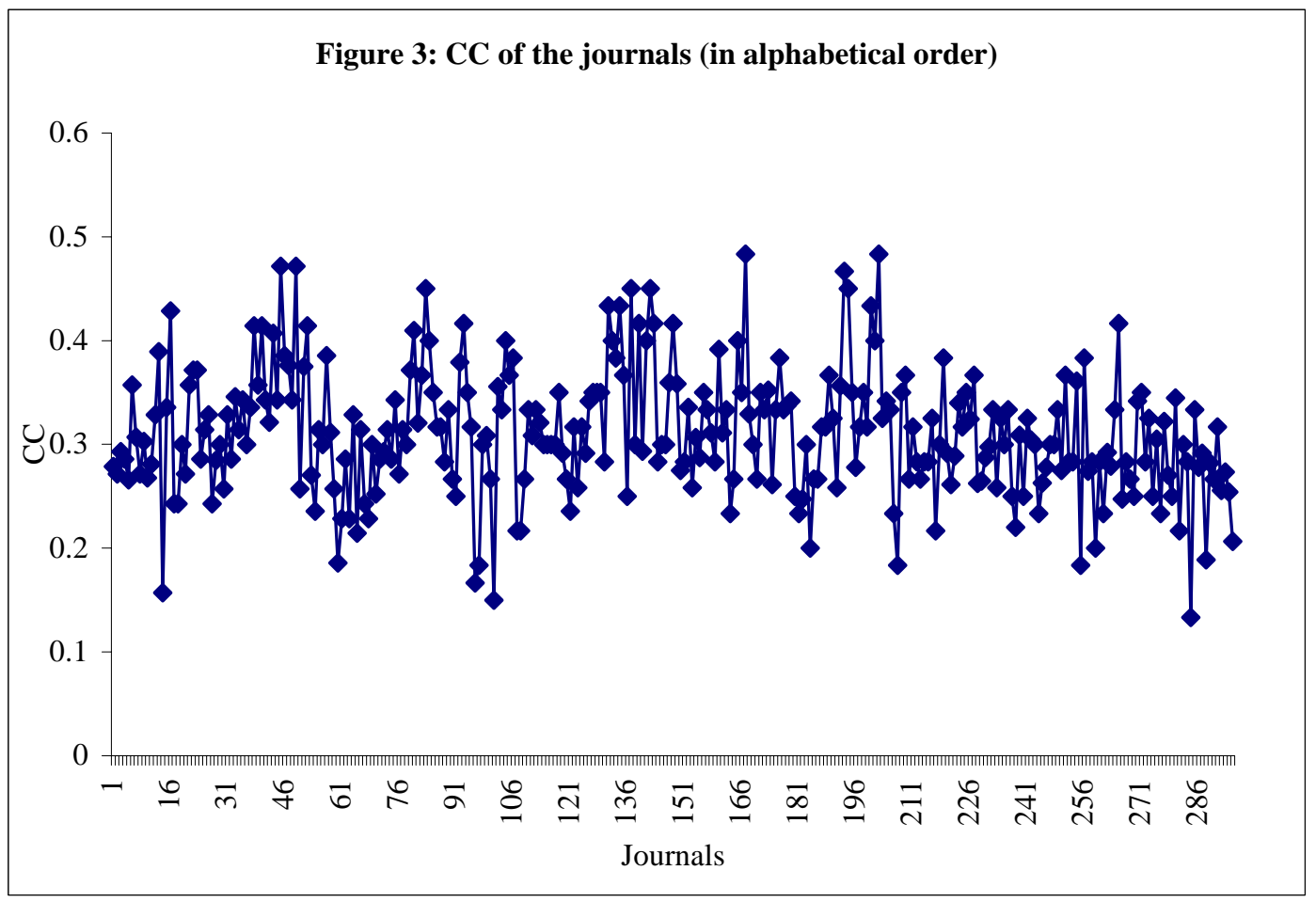

production of literature. This observation seems to fit Nigeria's scientific environment, which is widely known to be erratic, discontinuous, and fragmented—attributable mainly to many political, socio-economic, and environmental factors. These factors include decades of colonialism followed by decades of home-grown authoritarian governments dominated by the military hegemony; a chronic lack of transparency in national economic transactions, often accompanied by corruption; unsustainable use of natural resources; and marginal participation in the global economy (Gaillard, 1996; Onyeonoru, 1996). These factors negatively affected the activities of research institutions and universities: the morale of the scientists was dampened by poor remuneration, unsafe working environments, low educational budget, among other conditions, all of which resulted in a 
brain drain, causing the best brains in the universities and research institutions to flee to the developed countries and their industries. The mass exit of medical scholars from the

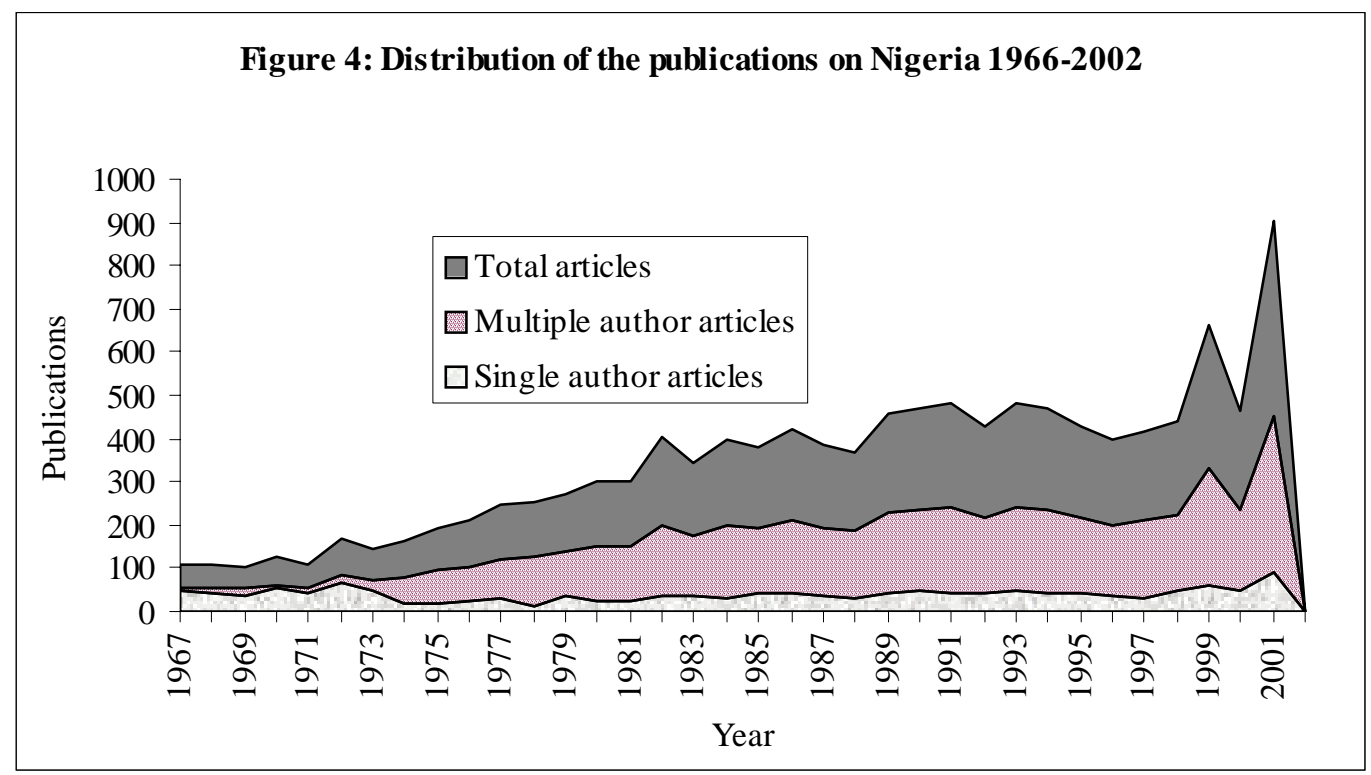

University College Hospital Ibadan, the foremost teaching hospital in Nigeria during the 1990s, epitomizes this situation (Osuntokun et al., 1992). The sharp rise in the production of literature from 1999 through 2002 can therefore be attributed to the relatively improved work environment, though short-lived, accompanying the democratic

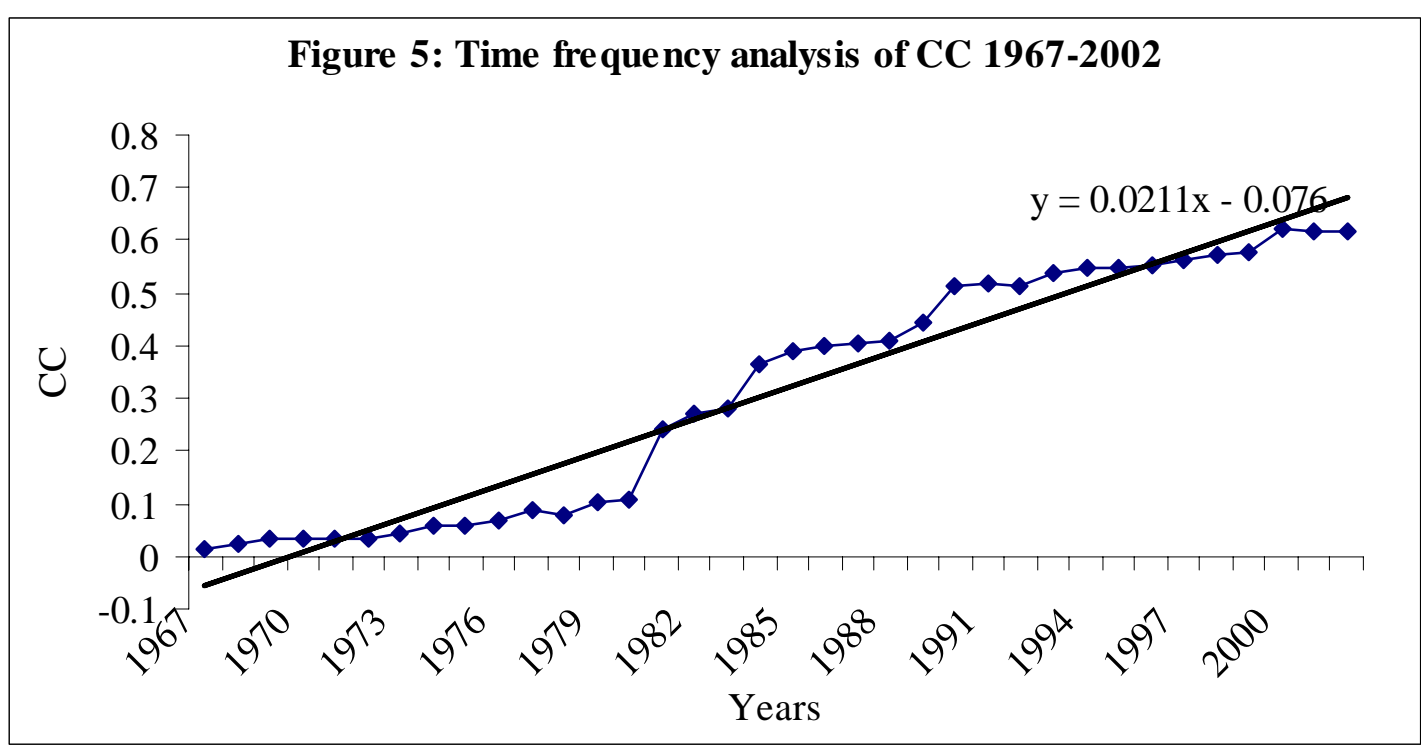

$\operatorname{Pg} 10$ 
government of President Olusegun Obasanjo in 1999. The distribution of authorship also shows great variation. The collaborative coefficient for the papers ranges from 0.012 to 0.680. The pattern of collaboration during the period is shown in Figure 5. It would appear that, despite the environmental factors that affected publication activities as we have noted, collaboration seems to have grown steadily although a fractional slope and a negative intercept would not indicate a rapid growth. Figure 5 also shows that the periods of the 1980s and the 1990s, during which repressive military governments were in power much of the time, witnessed increased collaboration. Ironically, although we have noted increased literature production during the civilian regime of the late 90s, collaboration does not seem to show correspondent growth. We can suggest that while policies and other activities of repressive governments since the early 1960s brought about a reduction in the quantity of publications, the scientists who remained in the research institutions seem to have retained collaboration as a research strategy to write scientific papers.

\section{Distribution of the journals and publications by subject heading}

Table 1 shows that multidisciplinary journals (41\%) outweighed other categories used by scientists publishing on Nigeria. Broad subject journals followed with $25 \%$, while the others category accounted for $21 \%$ of the journals. Furthermore, problem-centred journals accounted for about $5 \%$ while fission and fusion accounted for $6 \%$ and $3 \%$ of the journals respectively. During each of the periods, multidisciplinary journals led the journal channel choices of the scientists. The multidisciplinary journals contained 
Table 1: Distribution of the journal by subject heading (\%)

\begin{tabular}{|l|l|l|l|l|l|l|l|l|}
\hline Subject heading & $1967-972$ & $1973-978$ & 1979984 & $1985-990$ & $1991-996$ & $1997-002$ & Total \\
\hline Multidisciplinary & 35.0 & 45.7 & 40.4 & 33.9 & 42.3 & 46.8 & $\mathbf{4 1 . 0}$ \\
\hline Broad subject & 27.5 & 25.7 & 23.4 & 23.8 & 34.7 & 17.8 & $\mathbf{2 5 . 0}$ \\
\hline Fission & 5.0 & 11.4 & 8.5 & 5.0 & 1.9 & 4.8 & $\mathbf{5 . 6}$ \\
\hline Fusion & 2.5 & 2.8 & 2.12 & 1.7 & 1.9 & 4.8 & 2.7 \\
\hline Problem-centred & 10.0 & 2.8 & 2.12 & 6.8 & 1.9 & 6.5 & $\mathbf{5 . 1}$ \\
\hline Others & 20.0 & 11.4 & 23.4 & 28.8 & 17.3 & 19.2 & $\mathbf{2 0 . 6}$ \\
\hline Total & $\mathbf{1 0 0}$ & $\mathbf{1 0 0}$ & $\mathbf{1 0 0}$ & $\mathbf{1 0 0}$ & $\mathbf{1 0 0}$ & $\mathbf{1 0 0}$ & $\mathbf{1 0 0}$ \\
\hline
\end{tabular}

more collaborated (0.48) than fusion (0.46), broad subject categories (0.45), and others category of papers ( $\mathrm{CC}=0.45)$. Problem-centred (0.43) and fission (0.43) have the lowest collaborative coefficients.

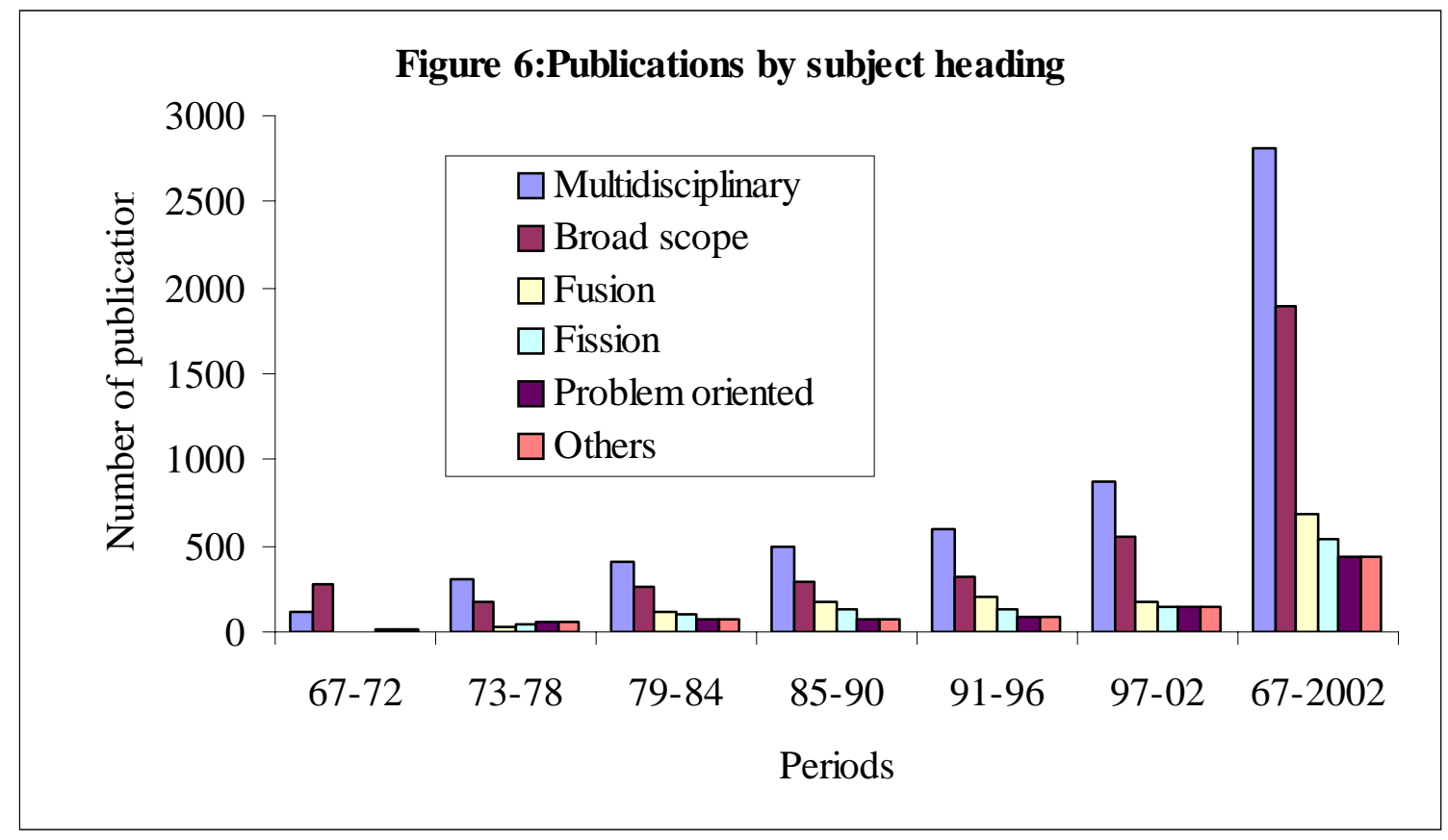

Multidisciplinarity also dominated the papers (Figure 6), with $41.17 \%$ of the publications being multidisciplinary during 1967-2002—almost double the number of papers attributable to the broad scope category (27.86\%). The fusion, fission, problemcentred, and others subject headings contributed 10.0\%, 8\%, 6.5\%, and $6.5 \%$ 
respectively for each of the periods. Figure 6 further shows that, except for 1967-1972, when broad scope papers outnumbered other categories, the multidisciplinary type of publications dominated others subject heading categories of the research papers written by Nigerian biomedical authors. Multidisciplinary papers were also more collaborative (0.48) than the other categories whose CC ranged between $0.42-0.45$.

\section{Distribution of papers by page number sizes}

Papers with 1-5 pages accounted for $61.89 \%$ of the publications while those with $6-11$, $12-15$, $>15$ pages accounted for $14.48 \%, 9.83 \%$, and $13.78 \%$ respectively. The CC for each page-number size category was $0.21,0.32,0.33$, and 0.34 respectively, indicating that collaborative coefficient increases marginally with increasing page number sizes. Page sizes seem to observe the same pattern all through the periods as there is no statistical association $\left(\mathrm{X}^{2}=3.126, \mathrm{~N}=22, \mathrm{p}=0.29\right)$ between page-number sizes and the time periods.

\section{Distribution of the journals by PIC}

We now turn to the significant issue of the quality of the journals through which Nigerian biomedical scientists published their papers as can be seen from PIC values in Figure 8. 
Figure 8: Distribution of Nigerian research journals by PIC

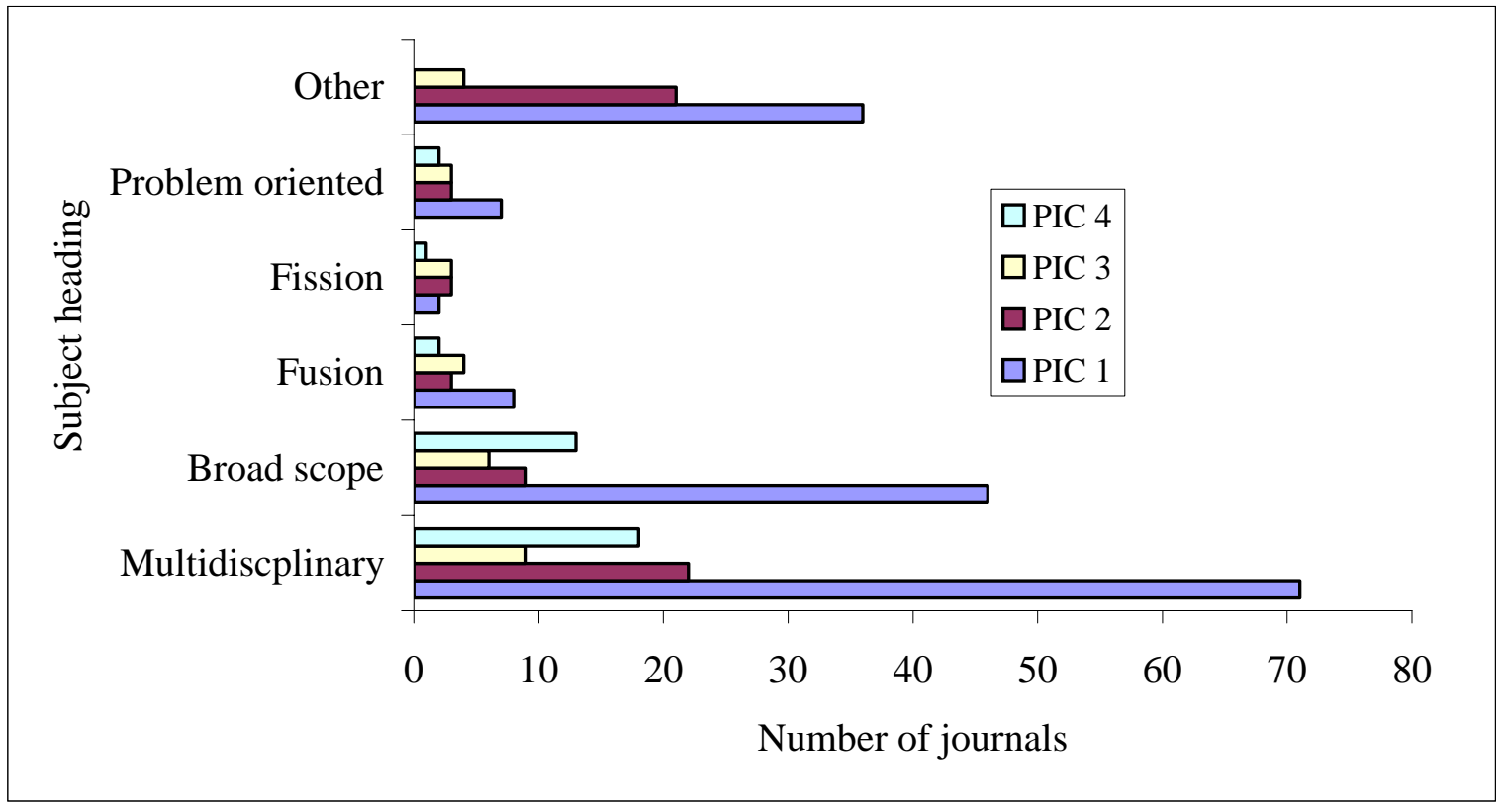

First, it shows that the distribution of papers by subject headings among the PIC categories has been extremely dissimilar, with a large proportion of each of the journal subject headings with journals that have their PIC below 6. Next it shows that multidisciplinary journals have the highest proportion of journals with PIC $>6$. Finally, we can notice the relatively high proportion of journals in the others category of the subject headings, none of which falls in the PIC 4 range.

So far, the result has shown the pattern of journal and article distribution during the period 1967-2002. We can see that in terms of core competency, Nigerian biomedical literature has had great multidisciplinary and broad-scope influence in research strategy. Fission, fusion, problem-centred journals and papers have not been as popularly used or produced as those of broad-scope and multidisciplinary. We can also deduce from the result that the quantity of literature has varied with several input variables such as period, subject heading, authorship, and page-number sizes of the papers. Papers of 1-5 pages 
size have dominated although papers with higher page number sizes have appeared to be more heavily co-authored. We have also seen that the distribution of papers between PIC categories has been dissimilar, with a large proportion of each of the journal subject heading categories having journals whose PIC is below 6 and with multidisciplinary journals having the highest proportion of journals with PIC $>6$.

Although none of the variables in this study can be considered entirely independent, we decided to tease out the determinants of the quantity of papers produced by the scientists by carrying out an SPSS analysis with specified input variables. The result of the analysis in Table 2 shows that the quantity of literature is significantly associated with authorship as well as multidisciplinary, broad scope, and others categories of subject headings of the journals. With respect to the papers by subject heading, there was an additional statistical significance with the others category, which implied that there was a high number of papers on Nigeria, which we could not classify by subject heading. Only the fission and problem-centred subject headings did not show any significant association with quantity of literature.

Hence, the multidisciplinary and broad-scope approach to research not only dominates the research strategy of the scientists but is also on the increase. The significant association between the quantity of literature and fusion category of papers would mean that there seems to be a growing number of papers that fall into the fusion category although such papers may have been published in other than the fusion category of journals. Fission and problem-centred papers do not seem to command strong influence in biomedical research in Nigeria. To allow for a non-uniform relationship with 
time, Figure 7 shows the relationship between the quantity of papers and the cube of the year of the publications.

Figure 7 bears a significant resemblance to the picture of the total papers with respect to time in Figure 4, which showed a nearly a straight-line pattern of growth during the period of the Nigerian civil war in 1967-1970 up to 1972. Although below the peak noticeable in 1973, when the effects of the civil war on formal scientific activities would seem to have relaxed, there was a very gentle rise in the number of publications, which continued until there was a drop in 1982. Another rise occurred in 1983, which also happened to be the peak of the second republic (1979-1983). Although

Table 2: SPSS analysis of quantity of literature as a function of other variables

\begin{tabular}{|c|l|l|}
\hline Parameter & Coefficient & Significance \\
\hline Authorship by Journals & 0.034 & $<0.01$ \\
\hline JSH- Multidisciplinary & 0.003 & $<0.01$ \\
Broad scope & 0.023 & $<0.01$ \\
Fission & -0.003 & ns \\
Fusion & 0.029 & ns \\
Problem-centred & -0.003 & ns \\
Others & 0.029 & $<0.01$ \\
\hline Authorship by Papers. & 0.019 & $<0.01$ \\
\hline ASH - Multidisciplinary & 0.103 & $<0.01$ \\
Broad scope & 0.013 & $<0.01$ \\
Fission & -0.041 & ns \\
Fusion & 0.129 & $<0.01$ \\
Problem-centred & -0.402 & ns \\
Others & 0.292 & $<0.01$ \\
\hline Page size & 1.110 & Ns \\
\hline
\end{tabular}


Figure 7: Relationship between quantities of literature with year assuming a cubic relationship

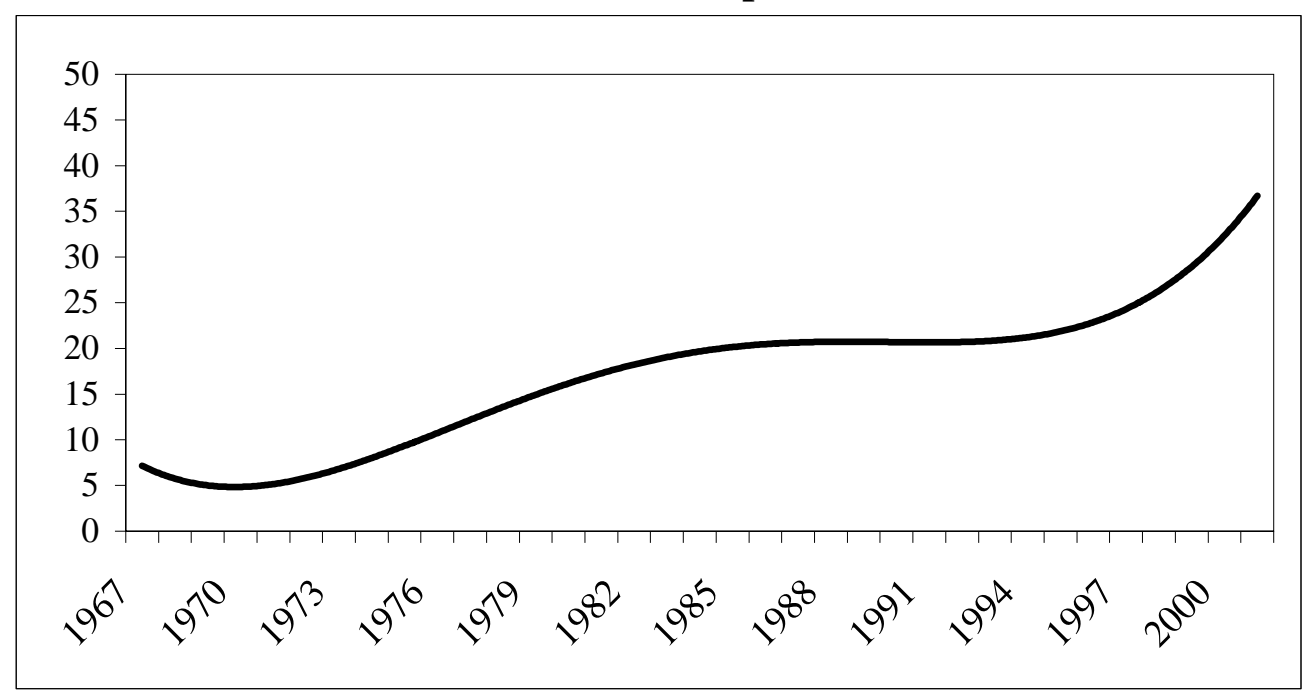

not as low as during the period before 1983, there was a decline in publications in 1989, followed by a rise through 1997 and prior to 1999 when publications seem to have increased astronomically.

The next area of examination was the impact of authorship on the other variables. The result in Table 3 below shows that authorship is significant in all the periods. While there is a major association between authorship and multidisciplinary, broad-scope, and others journals subject headings, authorship is not significantly associated with fission, fusion, and problem-centred categories, subject-heading categories that seem to be relatively less developed in Nigerian biomedical research. 
Table 3: SPSS analysis of authorship as a function of other variables

\begin{tabular}{|l|l|l|}
\hline Parameter & Coefficient & Significance \\
\hline Period & & \\
$1967-1972$ & 1.011 & $<0.01$ \\
$1973-1978$ & 0.031 & $<0.01$ \\
$1979-1984$ & 0.002 & $<0.01$ \\
$1985-1990$ & 0.023 & $<0.01$ \\
$1991-1996$ & 0.000 & $<0.01$ \\
$1997-2002$ & -0.003 & $<0.01$ \\
\hline Journal subject & & \\
heading & 0.342 & $<0.01$ \\
Multidisciplinary & 0.203 & $<0.01$ \\
Broad scope & -0.109 & $\mathrm{~ns}$ \\
Fission & 2.110 & $\mathrm{~ns}$ \\
Fusion & 0.961 & $\mathrm{~ns}$ \\
Problem-centred & 0.102 & $<0.01$ \\
Others & & \\
\hline Papers subject & & \\
heading & 2.211 & $<0.01$ \\
Multidisciplinary & 1.99 & $<0.01$ \\
Broad scope & 0.129 & $\mathrm{~ns}$ \\
Fission & 7.980 & $<0.01$ \\
Fusion & 0.291 & $\mathrm{~ns}$ \\
Problem-centred & -0.102 & $<0.01$ \\
Others & & \\
\hline Page number size & 3.11 & $<0.01$ \\
\hline
\end{tabular}

Authorship sizes by page-number sizes conformed to the global picture, which often shows that multiple authorship inflates article size. While the average number of pages per article was about five, higher page number sizes seemed to be associated with larger network sizes. Furthermore, although the number of authors and papers with pagenumber sizes between one and five were higher than the other categories, their collaborative indices were relatively lower than the papers with higher than five pages. Our result, however, differs from that of Steynberg and Roussouw (1995) regarding South African biomedical research that showed that there was no relationship between South African medical literature and the number of authors. This disparity might be 
accounted for by differences in the characteristics of used in the two studies. While Steinberg and Roussouw used a local South African citation index, namely South African Medical Database (SAMED), which might be more comprehensive for local channels, this present study relied on the international citation database Medline, which is very restrictive in relation to Nigerian local channels. This result conforms to that of Grant (1989) who has written on the trend towards multiple authorship in biomedical research. According to Grant, biomedical research projects are usually based on carefully

Table 4: SPSS analysis of PIC as a function of various input variables

\begin{tabular}{|l|l|l|}
\hline Variable & Coefficient & P \\
\hline Period & 0.187 & $\mathrm{~ns}$ \\
\hline Journal Subject & & \\
Heading & & \\
Multidisciplinary & 0.08 & $<0.01$ \\
Broad scope & 0.76 & $<0.01$ \\
Fission & -1.11 & $\mathrm{~ns}$ \\
Fusion & -1.09 & $<0.01$ \\
Problem-centred & 0.00 & $\mathrm{~ns}$ \\
Others & -0.11 & $\mathrm{~ns}$ \\
\hline Papers Subject & & \\
heading & & \\
Multidisciplinary & 1.01 & $<0.01$ \\
Broad scope & -0.09 & $<0.01$ \\
Fission & 2.00 & $\mathrm{~ns}$ \\
Fusion & -2.09 & $\mathrm{~ns}$ \\
Problem-centred & 0.01 & $\mathrm{~ns}$ \\
Others & -0.23 & $\mathrm{~ns}$ \\
\hline Page size & -0.51 & $\mathrm{~ns}$ \\
\hline
\end{tabular}

coordinated team efforts, often regarded as interdepartmental and multidisciplinary, and the reports frequently represent a consensus reached only after much vigorous discussion among all participants. The result of an analysis of this data using SPSS with PIC as the dependent variable is shown in Table 4. Both with respect to the journals and the papers, there is a significant association between PIC and multidisciplinary and broad scope journals and papers. A significant association also exists between PIC and fusion journals 
but not with fission papers, period, or page-number sizes of the papers since the coefficients are positive. With positive coefficients for multidisciplinary and broad scope journals, it would appear that scientists' opportunity to publish in journals with higher PIC lies in their choice of multidisciplinary or broad scope channels. While this observation holds for multidisciplinary papers, there is a difference with respect to broad scope papers where a negative coefficient suggests that scientists' use of broad scope journals reduces as their PIC values increase.

\section{Discussion and conclusion}

About $52 \%$ of all the journals that published papers on Nigeria did so only once each, whereas $48 \%$ appeared more than once in the bibliography. This result has implications for understanding the productivity of the scientists, their inconsistency in the use of channels, and their scramble to publish in any source that is willing to accept their papers, as well as an indication of the difficulty with which biomedical papers on Nigeria find their way into the international scientific community. Multidisciplinary research focus, followed by broad scope, dominated the strategies of Nigerian biomedical authors. Multidisciplinary channels are often believed to have implications of non-specialisation and lack of sharp focus in the research activities of the publishing scientists, whereas scientists in focused research areas customarily use specialised journals (Palmer, 1999). However, multidisciplinary journals often account for a larger proportion of the journals in circulation than the other categories of journals because multidisciplinary research groups or associations, which are capable of funding them, often own them. Also, since science thrives on publishing, scientists will have the tendency to use the channels that 
are available to them, and this may further explain the dominant use of multidisciplinary journals by Nigerian biomedical scientists.

Furthermore, multidisciplinary and broad scope journals reach a broader audience than fission, fusion, and other categories since each multidisciplinary journal has several disciplines whose interests are covered. Also, multidisciplinary journals have a wider market, often being subscribed to by members of the various disciplines that constitute the areas of focus of the journal. Hence, the relatively large number of multidisciplinary channels could also indicate that, socioeconomic circumstances notwithstanding, Nigerian biomedical scientists have struggled to reach a wider audience.

Fission type of research publications or sub-discipline-based publications that often indicate focus on specialisations as well as problem-centred papers focusing on specific instrumentation seem not to be popular among the scientists. We have shown elsewhere that basic research publications are on the decline in Nigeria although they are more heavily co-authored when they occur. There is, however, an indication that both the quantity of papers and the authorship are increasing in the fusion category of both journals and papers, indicating that interdisciplinary research is an increasing research strategy among Nigerian biomedical scientists, a finding that could explain why multiple authorship is also on the increase among Nigerian biomedical scientists (Nwagwu, 2005).

Research activities in Nigerian universities have shrunk over the years, with applied research dominating research strategies more than basic research. Practically, this orientation is expected because of the poor educational budget, poor laboratory facilities, and low technology, among others. It is therefore natural for scientists to make use of what is available to them, and this could account for the orientation in research activities. 
Moreover, during the long period of economic and political hardship in which higher educational institutions have had to struggle to survive, universities have evolved a research orientation and culture that they have passed on to the scientists they have trained.

In Nigeria, these observations will become very important in understanding the character of research because:

(i) the national educational budget has been drastically reduced since the oil glut in the 1970s;

(ii) specialised disciplines that could fall into the category of fission and problem-centred constitute small scientific communities that might not be able to sustain scientific journals in Nigeria;

(iii) governments do not fund or float any scientific journals; funds for floating journals often come from international agencies which themselves seem to prefer multidisciplinary focus; and

(iv) basic sciences are relatively absent because of the lack of required infrastructure facilities (Nwagwu, 2005).

\section{References}

Ajiferuke, I.S.Y, Burrel Q., Tague, J. (1988). Collaborative Coefficient: A Single Measure of the Degrees of Co-authorship in Research. Scientometrics 14(5-6) 421-433.

Brodman, E., \& Taine, S. I. (1959). Current medical literature: A quantitative survey of papers and journals. Proceedings of the International Conference on Scientific Information. Washington, D.C: National Academy of Sciences-National Research Council,. 435-447.

Gaillard, J. (1996). Science policies and cooperation in Africa. Knowledge, 14(2), 212226.

Grant I.W.B (1989). Multiple Authorship. British Medical Journal 298, 386-7. 
Klein, J. T. (1996). Interdisciplinarity: History, theory and practice. Detroit: Wayne State University.

Nwagwu, W. (2005). The landscape of biomedical research in Nigeria since 1967-2002. Learned Publishing, 18(3), 1-15.

Onyeonoru, I. P. (1996). Nature and management of students' conflicts. Ibadan Sociological Series, 4, pp. 34

Osuntokun, B. O, Ajayi, O. O., Adeuja, A. O. G., Adekunle,O. O., Shenjobi, M. P. I., Oyejide, C. O., Adio, P. A., Adetunji, M. A, \& Bankole, Z. O. (1992). The role and needs of tertiary care institutions in a Nigerian health information system. In Proceedings of the Conference on National Health Management Information System (NHMIS), December 1992, Abuja, Nigeria.

Palmer, C. L. (1999). Structures and strategies of interdisciplinary science. Journal of American Society for Information Science, 50(3), 244-247.

Prahalad, C. K., \& Hamel, G. (1990). The core competence of the corporation. Harvard Business Review, 68(3), 79-91.

Steynberg, S., \& Roussouw, S. F. (1995). Multiple authorship in biomedical papers: A South African case study. Journal of American Society for Information Science and Technology, 46(6), 468-472.

Webster, B. (2000). Polish Women in Science: a Bibliometric Analysis of Polish Science and its Publications 1980-1999. Research Evaluation 10(3). P185-194.

\section{Author's Note}

This article was extracted from a PhD thesis submitted in February 2005 at the Africa Regional Centre for Information Science (ARCIS) of the University of Ibadan, Nigeria. I must acknowledge Dr. Fabian Ehikhamenor, who supervised the thesis. The input of Dr. Ishola Ajiferuke of the School of Library and Information Science (SLIS), University of Western Ontario, Canada, is also acknowledged. 